Volume 13, Número 3, dezembro de 2019

Submetido em: 01/09/2019

Aprovado em: 22/11/2019

\title{
Que Emoção! Que Emoção?
}

\section{Such Emotion! What Emotion?}

\author{
Max Milliano Melo ${ }^{1}$
}

DIDI-HUBERMAN, Georges. Que emoção! Que emoção? São Paulo: Ed. 34, 2016.

\section{Resumo:}

No breve ensaio Que Emoção! Que Emoção?, Georges Didi-Huberman, a partir de referências que vão desde a filosofia clássica, ao cinema soviético, passando pela fotografia, literatura e psicanálise, discute a relação entre emoções e ações, defendendo seu papel mobilizador, numa crítica ao racionalismo, que opõe logos e pathos e relega a emoção a uma condição de desvio. Em uma defesa emocionada, o autor ressalta o caráter social das emoções e, por fim, sua potencialidade de mobilização social.

Palavras-chave: Imagem; Obras de Arte; Audiovisual; Emoção; Subjetividade.

\begin{abstract}
:
In the brief essay Such Emotion! What Emotion? Georges Didi-Huberman, using references from Classic Philosophy to Soviet Cinema, going through the literature, photography e psychoanalysis, discusses the relation between emotions and actions, advocating it mobilizing role, opposing to racionalism and its opposition between logos and pathos (that put the emotions as a deviation). In an emotional defense, the author emphasizes the social character of emotions and, finally, their potential for social mobilization.
\end{abstract}

Keywords: Image; Works of Art; Audiovisual; Emotion; subjectivity

A obra de Georges Didi-Huberman, um dos mais importantes intelectuais da atualidade, é marcada pela diversidade. Embora se defina como um historiador da arte,

\footnotetext{
${ }^{1}$ Doutorando e Mestre pelo Programa de Pós-Graduação em Mídia e Cotidiano (PPGMC) da Universidade Federal Fluminense (UFF), na linha de pesquisa Linguagens, Representações e Produção de Sentidos. Pesquisador vinculado ao Núcleo de Estudos e Experimentações do Audiovisual e Multimídia (Multis). E-mail: max.milliano.melo@gmail.com.
} 
seus escritos transitam também pela filosofia da imagem, o cinema, a televisão e a literatura. Neste trabalho, o autor, como o próprio título denuncia, se arrisca a pensar a emoção e sua relação com o eu, com o outro e, em especial, com as ações a partir da experiência estética e emocional que a obra de arte, particularmente a imagem, proporciona. O ensaio é a transcrição de uma breve conferência (e posterior sessão de perguntas) proferida pelo autor, em 13 de abril de 2013, em um auditório em Montreuil, nos arredores de Paris. O texto era um trecho do livro, àquela altura ainda em escrita, Peuples en Larmes, Peuples en Armes, lançado em 2016 na França e ainda inédito no Brasil $^{2}$.

A obra curta pode indicar a quem não conhece Didi-Huberman uma abordagem, digamos "ligeira". Ao contrário. Trata-se de reflexão densa, questionadora, que traduz, em linguagem - esta sim, simples e direta - uma proposta metodológica de fruição e interpretação da imagem. Um processo que se inicia desde o título do ensaio: uma mesma frase, primeiro como uma exclamação e, em seguida, como uma interrogação, revela a trajetória epistemológica do autor pois, se é inegável que a relação que se tem com a arte é, em um primeiro momento, a de encantamento, ao historiador, ao pesquisador ou para qualquer pessoa que se permita esse contato cabe, na sequência, compreender os sentidos, a dimensão e os processos de construção/linguagem proporcionados, justamente, por essa experiência estética e cultural tão intensa.

O percurso do autor, que nos leva pelas mãos didaticamente é, em um primeiro momento e sempre amparado por imagens - que vão desde ilustrações de um livro de Charles Darwin sobre as emoções dos seres vivos a frames de O Encouraçado Potemkin (Dir. Serguei Eisenstein, 1925) - discorrer sobre nosso encantamento diante das emoções extremas. Ali, Didi-Huberman reflete sobre como o choro - elemento que ele utiliza como condutor de seu pensamento sobre as emoções de maneira geral - a despeito de nossos mais violentos esforços, pode nos tomar de arroubo, fazendo-nos expor nossa face mais frágil e passível de ser julgada como "patética". O diagnóstico é anelado à lógica da cultura da sociedade ocidental que, segundo ele, sempre busca

\footnotetext{
2 A tradução para o português Povo em Armas, Povo em Lágrimas encontra-se em produção pela N-1 Edições.
} 
perseguir e aprisionar as lágrimas. Tal afirmação abre um leque argumentativo que tem a obra darwinista como referência, isto é, as emoções seriam sinônimo de primitivismo e, por isso mesmo, associadas aos menos racionais (como os animais, as crianças, as mulheres, os idosos e os não-europeus). Deste modo, em um processo metalinguístico, tomando a máxima Aristotélica de que a filosofia nasce do espanto, chega-se ao segundo ponto, resumido na segunda frase do título. A partir do espanto pela força de nossas emoções Didi-Huberman pergunta: que emoção?

Dialogando, rapidamente, com a história da filosofia ocidental, DidiHuberman vai, pontualmente, tecendo sua cadeia argumentativa que procura demonstrar como o processo de perseguição da emoção foi sendo associado ao primitivo e, portanto, é aquele que merece ser superado ou soterrado. Mais uma vez, coerente com seu método de construir uma exposição clara, didática mesmo, ele vai recuperando como, por exemplo, a oposição entre logos (razão, voz ativa) e pathos (paixão, voz passiva), típica da filosofia clássica (de Aristóteles a Kant), teria relegado às emoções à segunda categoria, ou seja, patética, aqui no moderno sentido pejorativo da palavra. Sob essa perspectiva passiva e oposta à razão, a emoção poderia ser compreendida como um impasse. "Impasse de linguagem (emocionado, fico mudo, não consigo achar palavras), impasse do pensamento (emocionado, perco todas as referências), impasse de ação (emocionado, fico de braços moles, incapaz de me mexer, como se uma serpente invisível me imobilizasse)." (DIDI-HUBERMAN, 2016, p. 21). Assim, este impasse - com toda a sua característica paralisante - seria a causa da visão negativa em torno da emoção, tida por Kant, por exemplo, como "um defeito da razão", "uma inabilidade de refletir", ou mesmo, "doença da alma". Deste modo, para os racionalistas, toda e qualquer emoção deveria ser suprimida para se abrir caminho à razão, esta sim, ativa, ligada à capacidade de ação e transformação do homem.

Discordando, diametralmente da visão exposta, Didi-Huberman rebela-se contra os racionalistas e se apoia em Hegel, Nietzsche, Sartre e Meleau-Ponty, fabulando um caminho que implica, acima de tudo, na recuperação da importância da emoção para a Filosofia. O pensamento niilista, em especial, é tido como um marco na reorientação do campo (de batalhas) filosófico, ao buscar na emotividade das artes, como a poesia de 


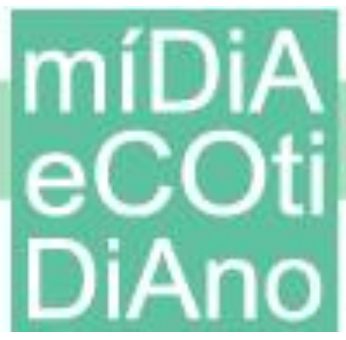

Baudelaire e a literatura de Flaubert, o questionamento da vida sensível. Com este percurso, a emoção é reposicionada pelo autor não como uma forma de imobilidade mas, de modo oposto, é reconhecida como promotora de uma ação - em um primeiro momento - aquela que expele algo que já não cabe dentro do homem. "Um movimento que consiste em nos por para fora de nós mesmos" (DIDI-HUBERMAN, 2016, p. 26).

Uma vez compreendido que a emoção retira algo de dentro de nós, Georges Didi-Huberman passa a refletir sobre essa relação da emoção com o eu. Acessando Freud, o autor comenta a nossa incapacidade de compreender por completo as emoções mais complexas, ou seja, haveria aqui um duplo movimento: de algo tão profundo que escapa à nossa capacidade racional (no campo do inconsciente) e, simultaneamente, externo à nós, algo que é posto para fora para, em seguida, perder-se no ar. Isto é, a emoção seria muito ampla do que o eu, já que não apenas se coloca em um espaço mais profundo que este, mas também, quando externalizado, depende do outro, do reconhecimento do outro para existir, sem que para isso perca sua autenticidade.

Para Didi-Huberman, a emoção urge ser pronunciada - pelo choro, pelos gritos - e, se ela é pronunciada é porque todo o grupo pode entendê-la! Um entendimento que circunscreve a emoção no território da linguagem e, como tal, nos ajuda a organizar o mundo (inclusive dentro de nós mesmos). "Nós nos manifestamos para nós mesmos ao exprimi-los para os outros e por conta dos outros. Trata-se essencialmente de uma simbologia”. (DIDI-HUBERMAN, 2016, p. 33). Ressalte-se, aqui, que o autor se debruça sobre a relação emoção-ação, isto é, emoções expressadas de forma privada (uma crise de choro sozinho no quarto, por exemplo) não despertaria uma ação concreta (pode-se chorar a noite toda e ir trabalhar no dia seguinte como se nada tivesse acontecido), portanto, seria uma situação que está fora do escopo de análise do filósofo francês.

A partir da constatação do caráter relacional e social da emoção - a história da arte, para Didi-Huberman, seria uma história das emoções figuradas - e reforçando sua defesa do caráter não-passivo das emoções, o autor dirige suas reflexões finais para não apenas renegar o caráter imobilizador das emoções, mas também para atribuir a elas um caráter mobilizador. Como na sequência de $O$ Encouraçado Potemkin, onde o choro dos cidadãos pela morte do marinheiro é, frame a frame, transformado em mobilização 
social e, por fim, luta revolucionária (Povo em Lágrimas, Povo em Armas), o autor defende a potencialidade transformadora da emoção (e do respeito às emoções). "Se não podemos fazer política efetiva apenas com sentimentos, tampouco podemos fazer boa política desqualificando nossas emoções, isto é, as emoções de toda e qualquer pessoa, as emoções de todos em qualquer um” (DIDI-HUBERMAN, 2016, p. 38, grifo do autor).

Em um mundo onde o capitalismo avançado produz desigualdades tão profundas quanto as crises sociais delas decorrentes, compreender o papel da emoção nas ações torna-se uma tarefa particularmente relevante. Com este breve texto, Georges DidiHuberman reafirma-se, para nós, como um dos mais importantes e decisivos autores que têm se debruçado sobre o papel das imagens e todo o processo de construção e representação que as envolvem. Aqui, suas reflexões que parecem, inicialmente, um diagnóstico restrito em seu foco na percepção das emoções como mobilizadoras do eu e do outro, logo se revelam muito mais amplas e potentes. São elas que nos convocam a percorrer, com ele, uma vereda fértil, tracejada por ser caráter interdisciplinar, mas sempre tendo como fundação o necessário e urgente viés dos questionamentos cotidianos como ingredientes fundamentais para a construção de um processo político e social partilhado, estético e humano. 